\title{
In Memoriam: Jonathan Baker
}

\section{Jytte Agergaard $^{1} \cdot$ Cecilia Tacoli $^{2} \cdot$ Griet Steel $^{3} \cdot$ Sinne Borby Ørtenblad $^{1}$}

In an academic career spanning over 40 years, Jonathan set the scene for much of the current work on rural-urban linkages in the Global South. His attention to the many ways in which people construct their daily livelihoods across the rural-urban divide, and how they manage to take advantage of national and local policy interventionsor, indeed, resist them-has deeply influenced a whole generation of researchers. Jonathan was a devoted academic to his last, and it is a huge honour to have his final paper included here. He was a good friend and a generous mentor to many, including the guest editors of this special issue that is dedicated to his memory.

Cecilia Tacoli

cecilia.tacoli@iied.org

Jytte Agergaard

ja@ign.ku.dk

Griet Steel

g.steel@uu.nl

Sinne Borby Ørtenblad

sinne@ign.ku.dk

1 Department of Geosciences and Natural Resource Management, University of Copenhagen, Øster Voldgade 10, 1350 Copenhagen, Denmark

2 International Institute for Environment and Development, 8086 Greys Inn Road, London WC1X 8NH, UK

3 Universiteit Utrecht, Vening Meineszgebouw A, 3584 CB Utrecht, The Netherlands 